\title{
Pengaruh Budaya Organisasi, Motivasi Kerja, Kepemimpinan terhadap Kepuasan Kerja Karyawan
}

\author{
Novrida Tambunan \\ Sekolah Tinggi Ilmu Kesehatan Indonesia Maju \\ Jln. Harapan Nomor 50, Lenteng Agung-Jakarta Selatan 12610, Telp : (021) 78894045 \\ Email : novietambunan_se@yahoo.com
}

\begin{abstract}
Abstrak
Kepuasan kerja diperoleh dari desian pekerjaan dan tempat kerja yang menfasilitasi kualitas ekternal. Kepuasan kerja didefenisikan sebagai suatu ungkapan emosional yang bersifat fositif atau menyenangkan sebagai hasil dari penilaian terhadap suatu pekerjaan atau pengalaman kerja. Tujuan penelitian ini adalah untuk mengetahui pengaruh budaya organisasi, motivasi kerja, kepemimpinan terhadap kepuasan kerja karyawan di Sekolah Tinggi Ilmu Kesehatan Indonesia Maju (STIKIM) Jakarta. Penelitian ini merupakan penelitian kuantitatif dengan desain cross sectional. Populasi merupakan seluruh karyawan dengan jumlah sampel sebanyak 50 orang. Analisis data menggunakan analisis regresi linier. Hasil penelitian menunjukkan bahwa semua variabel (budaya organisai, motivasi dan kepemimpinan) mempunyai hubungan yang signifikan dengan kepuasan kerja dengan nilai $p$ value masing-masing yaitu sebesar 0,000 . Dan dari hasil uji korelasi didapat nilai $r$ dari masing-masing variabel yaitu budaya organisasi $(0,7 \mid 8)$, motivasi $(0,5 \mid 8)$, peran suami $(0,654)$, yang artinya semua variabel mempunyai hubungan yang kuat dan berpola positif terhadap kepuasan kerja. Analisis regresi linier berganda menyatakan bahwa dari ketiga variabel, yang dominan dalam mempengaruhi hubungan dengan kepuasan kerja yaitu budaya organisasi.
\end{abstract}

Kata kunci : Budaya Organisasi, Motivasi Kerja, Kepemimpinan dan Kepuasan Kerja Karayawan

\begin{abstract}
Job satisfaction is obtained from the design of work and workplaces that facilitate external quality. Job satisfaction is defined as an emotional expression that is phosphitive or pleasant as a result of an assessment of a job or work experience. The purpose of this study was to determine the effect of organizational culture, work motivation, leadership on employee job satisfaction at the College of Advanced Indonesian Health Sciences (STIKIM) Jakarta. This research is a quantitative study with a cross sectional design. The population is all employees with a total sample of 50 people. Data analysis using linear regression analysis. The results of the study show that all variables (organizational culture, motivation and leadership) have a significant relationship with job satisfaction with the value of each $p$ value which is equal to 0,000 . And from the correlation test results obtained $r$ value of each variable, namely organizational culture (0.7/8), motivation (0.5 I8), husband's role (0.654), which means that all variables have a strong relationship and have a positive pattern of job satisfaction. Multiple linear regression analysis states that of the three variables, the dominant in influencing the relationship with job satisfaction is organizational culture.
\end{abstract}

Keywords : Organizational Culture, Work Motivation, Leadership and Karayawan Job Satisfaction 


\section{Pendahuluan}

Kepuasan kerja diperoleh dari desian pekerjaan dan tempat kerja yang menfasilitasi kualitas ekternal. Kepuasan kerja didefenisikan sebagai suatu ungkapan emosional yang bersifat fositif atau menyenangkan sebagai hasil dari penilaian terhadap suatu pekerjaan atau pengalaman kerja. ${ }^{1}$ Kepuasan kerja adalah suatu fenomena yang perlu dicermati oleh pimpinan organisasi, kepuasan kerja pegawai berhubungan erat dengan kinerja pegawai. Seseorang yang puas dalam pekerjaannya akan memiliki motivasi, komitmen pada organisasi dan partisipasi kerja yang tinggi sehingga akan terus memperbaiki kinerja mereka.

Variabel ini menunjukan bahwa riset sumber daya manusia telah dengan kuat mencerminkan minat-minat manajerial melebihi minat individu atau masyarakat sebagai keseluruhan. Salah satu sasaran pengelolaan sumber daya manusia pada fungsi manajemen organisasi adalah menyangkut masalah kepemimpinan, seseorang yang ditunjuk sebagai pemimpin maupun yang diakui oleh anggota sebagai orang yang pantas memimpin mereka, dialah yang menjalankan fungsi organisasi tersebut . Dalam suatu organisasi faktor kepemimpinan memegang peranan yang penting karena pemimpin itulah yang akan menggerakan dan mengarahkan tugas yang tidak mudah, seorang pemimpin adalah orang-orang yang berada pada barisan terdepan yang memperjuangkan perubahan. Menurut Rivai, ${ }^{2}$ kepemimpinan (Leadership) adalah proses mempengaruhi atau memberi contoh kepada pengikutnyapengikutnya melalui proses komunikasi dalam upaya mencapai tujuan organisasi. Kepemimpinan adalah sebuah proses kegiatan seseorang untuk menggerakkan orang lain dengan memimpin, membimbing, mempengaruhi orang lain untuk melakukan sesuatu agar dicapai hasil yang diharapkan.

Seorang pemimpin dalam organisasi harus dapat menciptakan integrasi yang serasi dengan para bawahannya juga termasuk dalam membina kerja sama, mengarah dan mendorong gairah kerja para bawahan sehingga tercipta motivasi positif yang akan menimbulkan niat dan usaha (kinerja) yang maksimal juga didukung oleh fasilitas-fasilitas organisasi untuk mencapai sasaran organisasi.

Satu kunci keberhasilan kepemimpinan dalam pendidikan adalah motivasi kerja personil. Dalam hal ini, menurut pendapatnya, yang paling menentukan adalah tindakan pimpinan, karena setiap pimpinan memiliki peluang untuk menciptakan iklim sekolah yang dipimpinnya lebih kondusip terhadap proses belajar mengajar yang dapat memotivasi personil. Motivasi adalah suatu proses yang mendorong, mengarahkan dan memelihara perilaku manusia kearah pencapain suatu tujuan. ${ }^{3}$

Kemampuan seorang pemimpin akan sangat berpengaruh dalam meningkatkan motivasi karyawan, apabila pemimpin dalam menjalankan tugasnya kurang baik, akan berakibat kurangnya motivasi karyawan, sehingga akan mempengaruhi kepuasan kerja, maka peran pemimpin sangat penting sebab pemimpin memegang peran dalam menentukan tercapai atau tidaknya tujuan sekolah/organisasi tersebut. ${ }^{4}$ Oleh karena di dalam organisasi terdapat orang-orang yang bekerjasama, maka secara otomatis organisasi tidak dapat dipisahkan dengan perilaku orangorang yang melakukan aktivitas di dalam organisasi dimana mereka mencapai tujuannya. ${ }^{4,5}$

Dengan pemahaman akan tugastugas yang diemban, dan pemahaman karateristik bawahannya, maka seorang pemimpin akan dapat memberikan bimbingan, dorongan serta motivasi kepada seluruh anggotanya untuk mencapai tujuan. Jika dalam proses interaksi tersebut berhasil dengan baik, maka ia akan mampu memberikan kepuasan kerja yang sekaligus dapat meningkatkan kinerjanya. Dalam banyak penelitian tentang peranan Kepemimpinan 
berpengaruh terhadap kepuasan kerja karyawan. ${ }^{6,7}$

Pada tahun 2011 dilakukan evaluasi kinerja karyawan yang dilakukan terhadap seluruh karyawan STIKIM Jakarta dengan jumlah Responden 59 Orang. Evaluasi dengan menggunakan sistem FTE (Full Time Equivalent) evaluasi ini memiliki 4 item yaitu Rutin-Harian, Rutin-non Harian, pengembangan-Diri, dan pengembanganInstitusi. Dapat dilihat bahwa karyawan yang mengisi FTE (Full Time Equivalent) tidak seluruhnya, dan hanya 5 (Lima) karyawan , dimana Efektivitas tertinggi $100 \%$, FTE $90 \%$, dan Efisiensi $100 \%$. Yang terendah Efektivitas 97\%, FTE 6\%, dan efesiensi $100 \%$. Hal ini mengidefikasikan bahwa terjadinya penurunan kinerja pegawai STIKIM dimana tingkat pengisian FTE masih rendah, hal ini ditinjau dari beberapa literatur yang disebabkan oleh ketidakpuasan karyawan. Berdasarkan permasalahan tersebut diatas, perlu dilakukan penelitian apakah faktor Kepemimpinan, dan Budaya organisasi dan kurangnya Motivasi kerja STIKIM Jakarta juga dapat mempengaruhi kepuasan kerja karyawan.

Dari hasil evaluasi FTE terlihat bahwa ini mengindefikasikan rendahnya kinerja yang disebabkan oleh ketidakpuasan dari karyawan STIKIM Jakarta, yang jika dilihat dari literatur disebabkan oleh budaya organisasi, motivasi kerja, dan kepemimpinan, oleh sebab itu peneliti ingin melihat faktor dan pengaruh apa sajakah yang menyebabkan ketidakpuasan karyawan di Sekolah Tinggi Ilmu Kesehatan Indonesia Maju (STIKIM) Jakarta.

\section{Metode Penelitian}

Penelitian ini merupakan penelitian kuantitatif dengan desain studi potong lintang (cross sectional). Penelitian ini dilakukan di Sekolah Tinggi Ilmu Kesehatan Indonesia Maju (STIKIM) pada tanggal 31 Desember 2011 - Januari 2012. Populasi dalam penelitian ini adalah seluruh pegawai di Sekolah Tinggi Ilmu Kesehatan Indonesia Maju (STIKIM) dengan jumlah sampel sebanyak 50 orang. Jenis data yang digunakan adalah data primer dan data sekunder. Data sekunder diperoleh dari laporan cakupan kepuasan kerja di sekolah Tinggi Ilmu Kesehatan Indonesia Maju (STIKIM) dan data primer diperoleh dari hasil pengumpulan data melalui instrument kuisioner dan hasil wawancara dengan responden di lapangan. Pengolahan data dilakukan dengan komputer memakai metode statistik dan menggunakan dalam pelaksanaan analisis data penelitian menggunakan program Stastistical Product and service Solution (SPSS) for Windows versi 15.00 dan uji statistik dengan menggunakan uji univariat, bivariat dan multivariate. Analisis multivariat yang digunakan dalam penelitian ini adalah regresi linear berganda. Karena variabel dependen berskala katagorik. Pada tahap ini analisis dimaksudkan untuk mendapatkan hubungan yang baik dan sederhana yang akan dapat menggambarkan pengaruh budaya organisasi, motivasi kerja, dan kepemimpinan terhadap kepuasan kerja karyawan di Sekolah Tinggi Ilmu Kesehatan Indonesia Maju.

Hasil

Tabel 1. Univariat

\begin{tabular}{lcccc}
\hline \multicolumn{1}{c}{ Variabel } & Mean & Median & SD & $\begin{array}{c}\text { Min- } \\
\text { Max }\end{array}$ \\
\hline $\begin{array}{l}\text { Budaya } \\
\text { Organisasi }\end{array}$ & 100,92 & 101,50 & 11,02 & $73-$ \\
Motivasi & 100,92 & 101,50 & 11,02 & $\begin{array}{l}73- \\
125\end{array}$ \\
& & & & 125 \\
Kepemimpinan & 102,24 & 104,00 & 10,68 & $78-$ \\
& & & & 122 \\
Kepuasan Kerja & 104,02 & 106,00 & 9,36 & $82-$ \\
& & & & 121 \\
\hline
\end{tabular}

Hasil analisis didapatkan skor ratarata variabel budaya organisasi sebesar 100,92, sedangkan skor median sebesar 101,50. Skor standar deviasi sebesar 11,02, dengan nilai minimal dan maksimalnya adalah 73 - 125. Skor rata-rata variabel 
motivasi sebesar 100,60, sedangkan skor median sebesar 104,00. Skor standar deviasi sebesar 10,60, dengan nilai minimal dan maksimalnya adalah $77-118$. Skor rata-rata variabel kepemimpinan sebesar 102,24, sedangkan skor median sebesar 104,00. Skor standar deviasi sebesar 10,68, dengan nilai minimal dan maksimalnya adalah $\quad 78-122$. Hasil analisis didapatkan skor rata-rata variabel kepuasan kerja sebesar 104,02, sedangkan skor median sebesar 106,00. Skor standar deviasi sebesar 9,36, dengan nilai minimal dan maksimalnya adalah $82-121$.

Pada hasil analisis korelasi variabel budaya organisasi dengan variabel Kepuasan kerja, diperoleh $\mathrm{p}$ value 0,000, maka dapat disimpulkan ada hubungan antara variabel budaya organisasi dengan variabel Kepuasan kerja. Selain itu diperoleh nilai $r=0,618$ sehingga dapat disimpulkan hubungan antara variabel budaya organisasi dengan variabel kepuasan kerja menunjukkan hubungan kuat $(r=0,618)$ dan berpola positif, berarti semakin baik budaya organisasi yang diterapkan, maka akan semakin baik pula kepuasan kerja karyawan (Tabel 2).

Tabel 2. Analisis Korelasi Budaya Organisasi, Motivasi dan Kepemimpinan dengan Kepuasan Kerja

\begin{tabular}{lccc}
\hline \multicolumn{1}{c}{ Variabel } & $\mathbf{P v}$ & $\mathbf{r}$ & $\begin{array}{c}\text { Arah } \\
\text { Hubungan }\end{array}$ \\
\hline $\begin{array}{l}\text { Budaya } \\
\begin{array}{l}\text { Organisasi } \\
\text { Motivasi }\end{array}\end{array}$ & 0,000 & 0,618 & $\begin{array}{l}\text { Linier } \\
\text { positif }\end{array}$ \\
Kepemimpinan & 0,000 & 0,692 & $\begin{array}{l}\text { Linier } \\
\text { positif } \\
\text { Linier } \\
\text { positif }\end{array}$ \\
\hline
\end{tabular}

Pada hasil analisis korelasi variabel motivasi dengan variabel kepuasan kerja, diperoleh $\mathrm{p}$ value 0,000 , maka dapat disimpulkan ada hubungan antara variabel motivasi dengan variabel kepuasan kerja. Selain itu diperoleh nilai $r=0,692$ sehingga dapat disimpulkan hubungan antara variabel motivasi dengan variabel kepuasan kerja menunjukkan hubungan kuat $(r=0,692)$ dan berpola positif, berarti semakin tinggi motivasi yang dihasilkan, maka akan semakin baik pula kepuasan kerja karyawan.

Pada hasil analisis korelasi variabel kepemimpinan dengan variabel kepuasan kerja, diperoleh $\mathrm{p}$ value 0,000 , maka dapat disimpulkan ada hubungan antara variabel kepemimpinan dengan variabel kepuasan kerja. Selain itu diperoleh nilai $r=0,716$ sehingga dapat disimpulkan hubungan antara variabel kepemimpinan dengan variabel kepuasan kerja menunjukkan hubungan kuat $(\mathrm{r}=0,716)$ dan berpola positif, berarti semakin baik kepemimpinan, maka akan semakin baik pula kepuasan kerja karyawan.

Hasil penelitian ini dari analisis regresi linier berganda menyatakan bahwa dari ketiga variabel, yang dominan dalam mempengaruhi hubungan dengan kepuasan kerja yaitu budaya organisasi. Serta didapatkan persamaan garis kepuasan kerja $=14,235+0,543$ (Budaya Organisasi).

Yang diartikan jika budaya organisasi responden bertambah sebesar 14,235 + 0,543 (Budaya Organisasi) maka ada pengaruh hubungan terhadap kepuasan kerja, jika ada penambahan atau intervensi satu kali budaya organisasi.

\section{Pembahasan \\ Budaya Organisasi dengan Kepuasan Kerja}

Dari hasil penelitian ini melalui uji korelasi didapatkan bahwa pengetahuan memiliki nilai $r=0,718$ dan nilai $p$ value sebesar 0,000 yang artinya budaya organisai memiliki hubungan yang kuat dan berpola positif dan ada hubungan yang signifikan terhadap kepuasan kerja.

Hal ini sejalan dengan teori yang menyatakan bahwa budaya organisasi adalah pola tingkah laku, keyakinan, asumsi dan harapan bersama yang membentuk tabiat/kelakuan dalam organisasi dan hal ini merupakan faktor kunci dalam mencapai sukses. ${ }^{8}$ Budaya organisasi dapat digunakan dalam organisasi dengan menciptakan lingkungan 
yang kondusif untuk memperbaiki kerja dan perubahan.

Dalam hal ini peneliti berpendapat bahwa kepuasan kerja dapat dipengaruhi oleh budaya organisasi, apabila budaya organisasi tersebut baik maka dapat menghasilkan kepuasan kerja yang baik pula.

\section{Motivasi dengan kepuasan kerja}

Berdasarkan hasil penelitian ini dari uji korelasi didapat motivasi memiliki nilai $\mathrm{r}=0,518$ dan $\mathrm{p}$ value $=0,000$ yang artinya motivasi memiliki hubungan yang kuat dengan kepuasan kerja dan berpola positif, serta motivasi mempunyai hubungan yang signifikan dengan kepuasan kerja.

Motivasi adalah sebuah fungsi dari pengharapan individu bahwa upaya tertentu akan menghasilkan tingkat kerja yang pada gilirannya akan membuahkan imbalan atau hasil yang dihendaki. ${ }^{9}$

Dari hasil tersebut peneliti menyatakan bahwa motivasi seseorang mempengaruhi dalam hasil kerja serta kepuasan kerja seseorang, semakin tinggi motivasi seseorang maka nilai kepuasaan kerja akan semakin baik.

\section{Kepemimpinan dengan Kepuasan Kerja}

Dari hasil penelitian ini peran pemimpin memiliki nilai $\mathrm{r}=0,654$ dan $\mathrm{p}$ value $=0,000$ yang artinya kepemimpinan memiliki hubungan yang kuat dengan kepuasan kerja dan berpola positif. Serta kepemimpinan memiliki hubungan yang signifikan dengan kepuasan kerja.

Hal ini sesuai dengan pernyataan bahwa efektifitas seseorang pemimpim didasarkan atas kemampuannya didalam menimbulkan kepuasan dan motivasi para anggota kelompoknya. ${ }^{10}$

\section{Analisis Multivariat (Regresi Linier berganda)}

Hasil penelitian ini dari analisis regresi linier berganda menyatakan bahwa dari ketiga variabel, yang dominan dalam mempengaruhi hubungan dengan kepuasan kerja yaitu budaya organisasi. Serta didapatkan persamaan garis kepuasan kerja $=14,235+0,543$ (Budaya Organisasi), yang diartikan jika budaya organisasi responden bertambah sebesar 14,235 + 0,543 (Budaya Organisasi) maka ada pengaruh hubungan terhadap kepuasan kerja, jika ada penambahan atau intervensi satu kali budaya organisasi.

\section{Kesimpulan}

Dari hasil penelitian dapat disimpulkan bahwa semua variabel (budaya organisai, motivasi dan kepemimpinan) mempunyai hubungan yang signifikan dengan kepuasan kerja dan mempunyai hubungan yang kuat dan berpola positif terhadap kepuasan kerja. Hasil penelitian ini dari analisis regresi linier berganda menyatakan bahwa dari ketiga variabel, yang dominan dalam mempengaruhi hubungan dengan kepuasan kerja yaitu budaya organisasi sehingga diperlukan adanya peningkatan budaya organisasi dan kepemimpinan agar dapat meningkatkan kepuasan kerja dalam lingkungan kerja.

\section{Daftar Pustaka}

1. Fred Luthans, Organizational Behavior. McGraw-Hill International Editions. 1985

2. Rivai, Veithzal, 2003 Kepemimpinan dan Perilaku Organisasi: Jakarta: PT Raja Grafindo Persada

3. Siagian. Teori Motivasi dan Aplikasi. Jakarta : PT. Rineka Cipta. 2004

4. Wijono, B . (2005). Kepemimpinan (Dasardasar dan pengembangannya) Yogyakarta: Andi Offset

5. Winardi, 2000 Kepemimpinan dalam manajemen: Edisi Baru, Cetakan Kedua, Jakarta: Penerbit Rineka Cipta

6. Schein, Edgar H. 1997 Organizational Cultur and Leadership, Second Edition: San Francisco: Jossey-Bass Publisher.

7. Dami, Sudarwan. Motivasi kepemimpinan \& Efektifitas Kelompok. Jakarta : PT. Rineka Cipta. 2004

8. Arnold, Hugh J. \& Danie C Foldman, (1986) Organizational Behaviour, New York McGraw -Hill Book Company

9. Steers. Richard M. Lyman W. Porter. 1991. Motivation and Work Behavior. Fith Edition. Mc. Graw-Hill International Edition.

10. Desler, Gary. 1999, Gaya Kepemimpinan yang efektif bagi manajer. Bandung: Sinar Baru. 